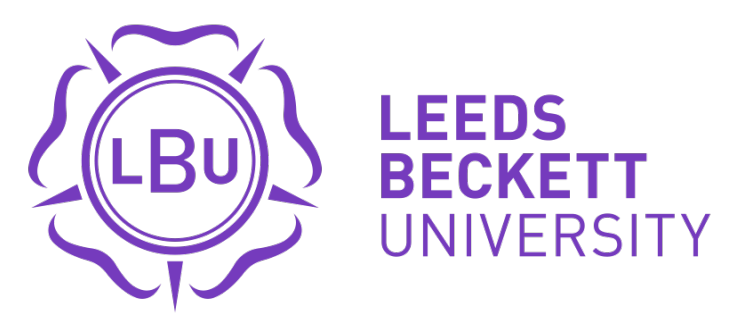

Citation:

Kaiseler, M and Queirós, C and Passos, F and Sousa, P (2014) Stress appraisal, coping, and work engagement among police recruits: an exploratory study. Psychological reports, 114 (2). 635 - 646. ISSN 0033-2941 DOI: https://doi.org/10.2466/01.16.PR0.114k21w2

Link to Leeds Beckett Repository record:

https://eprints.leedsbeckett.ac.uk/id/eprint/67/

Document Version:

Article (Published Version)

The aim of the Leeds Beckett Repository is to provide open access to our research, as required by funder policies and permitted by publishers and copyright law.

The Leeds Beckett repository holds a wide range of publications, each of which has been checked for copyright and the relevant embargo period has been applied by the Research Services team.

We operate on a standard take-down policy. If you are the author or publisher of an output and you would like it removed from the repository, please contact us and we will investigate on a case-by-case basis.

Each thesis in the repository has been cleared where necessary by the author for third party copyright. If you would like a thesis to be removed from the repository or believe there is an issue with copyright, please contact us on openaccess@leedsbeckett.ac.uk and we will investigate on a case-by-case basis. 


\title{
STRESS APPRAISAL, COPING, AND WORK ENGAGEMENT AMONG POLICE RECRUITS: AN EXPLORATORY STUDY ${ }^{1,2}$
}

\author{
MARIANA KAISELER \\ Institute for Sport, Physical Activity and \\ Leisure, Leeds Metropolitan University, UK
}

FERNANDO PASSOS

\author{
Polícia de Segurança Pública \\ Lisboa, Portugal
}

\author{
CRISTINA QUEIRÓS \\ Universidade do Porto, Porto, Portugal
}

PEDRO SOUSA

Escola Prática de Polícia

Torres Novas, Portugal

\begin{abstract}
Summary-This study investigated the influence of stress appraisal and coping on work engagement levels (Absorption, Vigour and Dedication) of police recruits. Participants were 387 men, ages 20 to 33 years $(M=24.1, S D=2.4)$, in their last month of academy training before becoming police officers. Partially in support of predictions, work engagement was associated with Stressor control perceived, but not Stress intensity experienced over a selfselected stressor. Although the three dimensions of work engagement were explained by Stressor control and coping, Absorption was the dimension better explained by these variables. Police recruits reporting higher Absorption, Vigour, and Dedication reported using more Active coping and less Behavioural disengagement. Results showed that stress appraisal and coping are important variables influencing work engagement among police recruits. Findings suggested that future applied interventions fostering work engagement among police recruits should reinforce perceptions of control over a stressor as well as Active coping strategies.
\end{abstract}

Work engagement refers to an employee's cognitive state, characterized by high motivation, and has been shown to be related to positive work-related outcomes (Yagil, 2012). Previous research has shown that job and personal resources are important correlates of work engagement (Bakker, 2009). Particularly, coping has shown to be associated with work engagement across different professions such as teachers (Parker \& Martin, 2009), college students (e.g., Gan, Yang, Zhou, \& Zhang, 2007), nurses, and police officers

\footnotetext{
1 Address correspondence to Mariana Kaiseler, Carnegie Faculty, Leeds Metropolitan University, Fairfax Hall 207, Headingley Campus, Leeds, LS6 3QT, UK or e-mail ( M.H.Kaiseler@) leedsmet.ac.uk ).

2 The authors wish to acknowledge the support and cooperation of the Escola Prática de Polícia, Portugal (EPP) staff and students in conducting this research. The research has received funding from the European Union Seventh Framework Programme (FP7/2007-2013) under grant agreement no. PCIG10-GA-2011-303880 and from Fundação para a Ciência e Tecnologia

(FCT), Portugal under project DFRH/BI/51845/2012 and project PEst-OE/PSI/UI0050/2014.
} 
(Rothmann, Jorgensen, \& Hill, 2011). Although these studies supported the association between coping and engagement across professions, the conclusions were limited due to the variety of coping definitions and conceptualizations used. Furthermore, stress appraisal was not contemplated in the coping assessment as recommended by Cooper, Dewe, and O'Driscoll (2001). Police work is one of the most stressful occupations (McCarty, Zhao, \& Garland, 2007) and recruits face a demanding, isolated and extensive training period in the academy (Wilson \& Grammich, 2009; Heslop, 2010). The current exploratory study adopted a proactive research perspective and investigated, based on the transactional model, the influence of stress appraisal and coping on work engagement of police recruits. Findings will inform the design of efficient coping intervention in the training of future police officers (Bakker \& Demerouti, 2008; LeBlanc, Regehr, Jelley, \& Barath, 2008; Maas \& Spinath, 2012).

Coping was defined by Lazarus and Folkman (1984, p.141) as a "constantly changing cognitive and behavioural efforts to manage specific external and/or internal demands that are appraised as taxing or exceeding the resources of the person." Two types of cognitive appraisal are associated with the coping process. Primary appraisal is the individual judgment of the demands of a stressful event in relation to the person's goals and values and is associated with the stress experienced. Secondary appraisal involves the evaluation of coping responses that may be required to manage the demands of the event and reflects the extent to which one perceives potentially having control, as well as the belief one can successfully perform the behaviours necessary to deal with the situation (Lazarus \& Folkman, 1984). Both primary and secondary appraisals have been found to be important predictors of coping (Aldwin, 2007).

Although the transactional definition of coping is the most frequently cited, it has not been much used in workplace stress research, mainly due to difficulties in generalization of findings (Harris, 1991). Nevertheless, as suggested by Lazarus (1991), sources of stress are always personal and idiosyncratic as are the coping strategies that people use. Despite this fact, while workplace stress researchers acknowledge the explanatory potential of the appraisal process, they have not always given attention to this construct (Dewe, O'Driscoll, \& Cooper, 2010). This limitation results in ignoring how the person gives meaning to the event, as well as the foundations and context on which coping decisions are made (Lazarus \& Folkman, 1984).

Although previous studies in both psychology and criminal justice investigating stress among police officers were crucial to the understanding of work stress in this population and organizational performance, they have been plagued by two main limitations. Firstly, the research focus has been the association between psychological distress and coping (Brown \& Campbell, 1994; Toch, 2002), as opposed to human strengths, optimal functioning, and engagement (Seligman \& Csikszentmihalyi, 2000; Richardsen, Burke, \& Martinussen, 2006). Particularly, it seems critical to understand the relationship between stress appraisal, coping, and engagement to prevent distress among police personnel, and identify efficient coping strategies. Secondly, the assessment of stress and coping among police recruits undergoing academy training has not received much attention. Violanti (1992) noted that during the first contact with their future profession, police recruits are subject to intense physical and psychological stress, and are also deprived of outside support. Additionally, from a stress management and prevention perspective (Giga, Cooper, \& Faragher, 2003), there is a need to conduct research among police recruits in training, with the goal of reducing police officers' later stress. 
Police academy training situations provide a natural and privileged setting for the investigation of the relationships between situational stress, personal appraisal, and coping (Coyne, Aldwin, \& Lazarus, 1981). Hence, addressing previous research limitations, the influence of stress appraisal and coping on work engagement was investigated among police recruits undergoing their last month of academy training. Considering that this study was exploratory in nature, no predictions were made for coping strategies associated with engagement after controlling for stress appraisal; however, since work engagement has been associated previously with positive affective states and successful academic performance (Schaufeli, Martínez, Marques Pinto, Salanova, \& Bakker, 2002; Bakker, 2009):

Hypothesis. Police recruits with higher work engagement would perceive lower stress intensity, and higher stressor control when appraising a self-selected stressor.

\section{METHOD}

\section{Participants}

A non-probabilistic sample participated in the current study. Participants were 387 Portuguese male police recruits enrolled in the Police Academy for the academic year 2010/2011. Participants average age was 24.06 years old $(S D=2.38)$. Educational background included the Certificates of Secondary Education $(n=362)$ and Bachelor's degrees $(n=25)$. Data were collected in the last month of training, just before participants became police officers. The study was approved by the University and Police Academy Ethics Committees and recruits provided informed consent prior to participating.

\section{Measures}

Stressor type and stressor appraisal.-In accordance with Lazarus and Folkman's framework (1984), a stressor was self-selected and assessed using an open-ended question. Participants wrote down the most intense stressor related with the academy course experienced in the last 14 days. Following this, they reported their primary appraisal of the stressor by indicating how much stress the event caused, and their secondary appraisal by indicating how much control they perceived they had over the stressor. Responses were recorded on a Likert scale with response anchors 1: Not at all stressful and 5: Extremely stressful, or 1: No control at all and 5: Full control. This approach was similar to that used in previous research in the area of stress appraisal and coping (e.g., Kaiseler Polman, \& Nicholls, 2009, 2012).

Coping.-Following completion of stress appraisal, participants completed the Brief COPE (Carver, 1997) translated and adapted to Portuguese by Pais-Ribeiro \& Rodriques, (2004). The Brief COPE asks participants to indicate how much they use a particular coping strategy during a stressful event and includes 14 coping strategies, with two items representing each subscale. Table 1 defines the classification of coping used in the present study. Each item is scored on a four-point scale with anchors 0 : I haven't been doing this at all and 3: I've been doing this a lot. Evidence supports the reliability of the Brief Cope and its validation among the Portuguese population (Pais-Ribeiro \& Rodriques, 2004) founding values that support an identical pattern of translations among different countries (Sica, Novara, Dorz, \& Sanavio, 1997). Cronbach's $\alpha$ values found in the current study ranged between .63 and .94 similarly to those presented originally by Carver (1997), and in the Portuguese version by Pais-Ribeiro 
\& Rodrigues (2004) (see Table 1). Additionally, the fourteen coping strategies explained $83.9 \%$ of total variance among our data, while for Carver (1997) they explained $72.4 \%$ and for Pais-Ribeiro \& Rodrigues they explained 67.5\%. Test-retest analysis of coping strategies are not frequently referred (Carver, 1997), but recently Cooper, Katona, and Livingston (2008) found $r=0.32$ after 2 year and Yusof, Low and Yip (2010), found that test-retest Intraclass Correlation Coefficient ranged from .05 to 1.00 . Due to the potentially poor reliability results found for two-item scales in this study (Eisinga, Grotenhuis, \& Pelzer, 2013), the Spearman-Brown formula was calculated (Table 1), presenting similar values to Cronbach's $\alpha$ for almost all variables. Although some of the coping subscales showed low internal consistency, it was decided to include these in the statistical analysis. As shown in previous coping research (e.g., Kaiseler, et al., 2009, 2012) estimates of internal consistency have limited applicability when assessing psychometric properties of coping measures (Billings \& Moos, 1981). For example, one coping strategy may be appropriate to relieve stress and as such would not require additional responses from either the same category or other categories of coping.

Engagement.-Engagement was assessed with the 17-item Utrecht Work Engagement Scale (UWES) Schaufeli and Baker (2003) translated and adapted to Portuguese by Schaufeli, Martinez, Pinto, Salanova, and Bakker (2002). The scale includes three subscales: Vigour (six items), Dedication (five items), and Absorption (six items), all scored on a sevenpoint scale with anchors 0 : Never in the past year, and 6: Every day. Evidence supports the internal consistency and reliability of the UWES and its validation among the Portuguese population (Schaufeli et al., 2002). Cronbach's as values found in this study were between .84 and .92 similar to those presented originally in the technical manual (Schaufeli \& Baker, 2003), or Portuguese version (Schaufeli et al., 2002) (see Table 1). Additionally, the three subscales present two year stability scores between .30 and .46 (Schaufeli \& Baker, 2003).

\section{Procedure}

Following ethics approval, digital letters were sent to academy police recruits by e-mail, providing details about the study and encouraging participation. Voluntary participants completed a consent form, and a web-based survey available on the academy Moddle web platform. After reading a significant number of reported stressors by the participants, responses were classified into two main categories: (a) outcome (theoretical and practical results, e.g., "I am worried about the result of a theory test"), (b) course (structure and performance, e.g., "Unsure how to organize my time management and study priorities"). The first and second author independently coded the full sample. The two coders agreed on 365 out of the 387 stressors (94\%) reported. In the cases of disagreement, discussion followed with the third and fourth authors and a decision was made. These data were used for statistical analysis.

\section{Analysis}

After screening for outliers and normality, Cronbach's as and descriptive statistics for all study variables were calculated (see Table 1). Following this, correlations between the variables were calculated. To investigate whether the type of stressor reported influenced engagement, an independent-samples $t$ test was conducted. Hierarchical regression analyses were only conducted for the significant correlations found between stress appraisal, coping, and the three subscales of the Utrecht Work Engagement Scale. Following previous research 
recommendations (Shimazu, Schaufeli, Kosugi, Suzuki, Nashiwa, Kato, et al., 2008; e.g., Nerstad, Richardsen, \& Martinussen, 2010), and in accordance with the goals of the study, the three dimensions of engagement were analyzed independently, instead of separately. Multiple linear hierarchal regression analyses (stepwise) were performed to investigate the relationship between the three dimensions of engagement (dependent variable), and the use of coping strategies, whilst controlling for stress appraisal, using scale dimensions as ratio values.

\section{RESULTS}

Table 1 provides the means, standard deviations and psychometric information for the Brief Cope, and the Utrecht Work Engagement Subscales, Stress intensity, and Stressor control. The Kolmogorov-Smirnov test showed an absence of normality in the distribution of all variables, suggesting the use of non-parametric tests (Table 1). However, the sample has more than 30 participants $(N=387)$, and according to Central Limit Theorem of probability theory, when the sample size increases, the distribution of the mean approaches to a normal distribution (Barnes, 1994). Additionally, skewness was less than 3, and kurtosis less than 7 (Kline, 2005), suggesting that the results were not affected by non-normality. The only exception was the coping strategy "Substance use" which had a low mean. This result can be explained by the fact that police recruits are not allowed to use drugs or alcohol during academy training.

\section{[Table 1]}

No differences were found in engagement levels across the two categories of stressor experienced $(p>.05)$. Table 2 provides the correlations between the three subscales of Utrecht Work Engagement Scale, Stress intensity, Stressor control, and coping. The different dimensions of Engagement influenced Stressor control but not Stress intensity, and had a diverse influence on coping. The correlational analysis partly supported a priori predictions that engagement is associated with stress appraisal and coping. Moreover, Dedication was weakly related with coping strategies, while Absorption was more strongly related with coping strategies. Additionally, Stressor control and Active coping were positive correlated with engagement dimensions, while Behavioural disengagement presented negative correlations.

\section{[Table 2]}

Table 3 presents the results of the multiple linear hierarchal regression analyses (stepwise) to assess whether the use of coping strategies predicted the three dimensions of engagement, while controlling for Stressor control. All three dimensions of engagement were dependent variables, Stressor control was entered at Step 1, and the coping subscales were entered at Step 2 as predictor variables. Results showed that of the three dimensions of engagement, Absorption was unique explained (14.9\%) by the predicted model, followed by Vigour $(11.1 \%)$, and last Dedication $(9.5 \%)$. Stressor control was a positive predictor for the three subscales of Engagement. Lower Behavioural disengagement was associated with higher Active coping and predicted theoretically important amounts of variance in Absorption, Vigour, and Dedication among police recruits. Religious coping predicted only Vigour and Dedication. Finally, less use of Self-blame predicted only Vigour among police recruits. 


\section{DISCUSSION}

The results suggest that stress appraisal is an important variable to consider when investigating the relationship between coping and work engagement among police recruits. Particularly, partially in accordance with prior predictions, police recruits with higher engagement scores reported higher scores on Stressor control over their self-selected stressor. This may be explained by the notion that individuals experiencing a high sense of control over an event are also more likely to perceive a challenge in regard to the stressful situation (Lazarus \& Folkman, 1984). Future research considering the meaning of stress appraisals is required to confirm this argument. These findings reinforce the suggestion that perceptions of control are associated with positive outcomes across a variety of settings (Thompson \& Spacapan, 1991). On the other hand, contrary to prior predictions, police recruits with higher engagement scores did not differ from those with lower scores on ratings of Stress intensity. These findings suggest that the intensity of stress appraised over a self-selected stressor is not related to work engagement among police recruits. It would be interesting to understand whether these findings are replicated among active-duty police officers.

The magnitude of most of the correlations obtained in the present study between stress appraisal, coping, and the three dimensions of engagement were weak. However, the direction of the correlations found suggested that police recruits reporting higher Absorption, Vigour and Dedication also reported higher Stressor control and use of more Active coping and Planning. These findings support previous literature in the area, suggesting that work engagement considers a variety of job and personal resources (Bakker, 2009). On the other hand, these individuals tended to use less Behavioural disengagement, in line with previous research associating the use of problem-focused coping to better well-being (e.g., Ayree, Luk, Leung, \& Lo, 1999; Penley, Tomaka, \& Wiebe, 2002).

The regression analysis showed that Stressor control and some coping strategies predicted variance in the three subscales of work engagement among police recruits. The variance explained by the model was different across the three subscales of work engagement, from $9.5 \%$ to $14.9 \%$. Mirroring the correlation findings, Dedication was the subscale less explained by the variables Stressor control and coping, in agreement with Bakker (2009). Dedication refers to the individual being strongly involved in his work and experiencing significance, enthusiasm, and challenge, so this subscale should be predicted by job resources, rather than personal resources. Absorption refers to the individual being highly concentrated and happily involved in his work, so as observed, it should be more dependent on personal resources such as perceptions of control over a stressor and use of coping strategies. These findings provide support for the need to investigate the three subscales of engagement independently (Shimazu, et al., 2008; e.g., Nerstad, et al., 2010), rather than analyzing work engagement separately, to provide more specific information for applied interventions.

When analyzing coping strategies predicting work engagement, it was found that the use of more Active coping and less Behavioural disengagement predicted higher Absorption, Vigour and Dedication among police recruits. Since Active coping involves taking active steps to overcome the stressor (Carver, Scheier, \& Weintraub, 1989), it is believed that this coping strategy was more used by engaged police recruits to face the self-selected stressors. 
Behavioural disengagement involves actions that disengage one from the situation (Carver, et al., 1989); its low use by police recruits can be possibly explained by the limited impact these actions have on facing stressors. When comparing these findings with previous research among South African police officers (Rothman et al., 2011), some similarities can be found. Rothman et al. concluded that higher engagement among police officers was predicted by the use of more Approach coping strategies including Problem-focused coping ( $\beta=0.27$ ), Seeking social support $(\beta=0.05)$, and Turning to religion $(\beta=0.07)$. However, these authors did not assess stress appraisal, and coping was analyzed at a dimensional level. Future longitudinal studies are required, to assess relations between stress appraisal, coping, and work engagement among police recruits in academy, and reassessing the population later on as police officers. Such longitudinal research approaches will provide instructions for applied coping interventions fostering work engagement among police recruits over training, and reinforcing or restructuring these according to police officer's needs (Patterson, Chung, \& Swan, 2012).

Findings from this exploratory study, suggest that future research should investigate the influence of other personal variables (e.g., personality traits, performance outcomes) on engagement among police recruits undergoing academy training.

\section{References}

Aldwin, C. M. (2007) Stress, coping and development - an integrative perspective ( $2^{\text {nd }}$ ed.) New York: Guilford Press.

Ayree, S., Luk, V., Leung, A., \& Lo, S. (1999) Role stressors, interrole conflict, and well-being: the moderating effect of spousal support and copping behaviours among employed parents in Hong Kong. Journal of Vocational Behaviour, 54, 259-278.

Bakker, A. B. (2009) Building engagement in the workplace. In R. J. Burke \& C. L. Cooper (Eds.), The peak performing organization. Oxon, UK: Routledge. Pp. 50-72.

Bakker, A. B., \& Demerouti, E. (2008) Towards a model of work engagement. Career Development International, 13, 209-223.

Barnes, J.W. (1994). Statistical analysis for engineers and scientists: a computer based approach. New York: McGraw-Hill.

Billings, A. G., \& Moos, R. H. (1981) The role of coping responses and social resources in attenuating the stress of life events. Journal of Behavioural Medicine, 4, 139-157.

Brown, J., \& Campbell, W. C. (1994) Stress and policing: sources and strategies. Work \& Stress, 8, $278-279$.

Carver, C. S. (1997) You want to measure coping but your protocol's too long: consider the Brief COPE. International Journal of Behavioural Medicine, 4, 92-100.

Carver, C. S., Scheier, M. F., \& Weintraub, J. K. (1989) Assessing coping strategies: a theoretically based approach. Journal of Personality and Social Psychology, 56, 267-283.

Cooper, C. L., Dewe, P. J., \& O'Driscoll, M. P. (2001) Organizational stress. A review and critique of theory, research, and applications. Thousand Oaks, CA: Sage Publications.

Cooper, C, Katona, C, \& Livingston G. (2008).Validity and reliability of the brief COPE in carers of people with dementia: the LASER-AD Study. Journal of Nervous and Mental Disease, 196(11), 838-843.

Coyne, J. C., Aldwin, C., \& Lazarus, R. S. (1981) Depression and coping in stressful episodes. Journal of Abnormal Psychology, 90, 439-447. 
Dewe, P. O., O’Driscoll, M. P., \& Cooper, C. L. (2010) Coping with work stress - a review and critique. Chichester, England: Wiley-Blackwell.

Eisinga, R., Grotenhuis, M., \& Pelzer, B. (2013). The reliability of a two-item scale: Pearson, Cronbach or Spearman-Brown? International Journal of Public Health, 58(4), 637-642.

Gan, Y., Yang, M., Zhou, Y., \& Zhang, Y. (2007) The two-factor structure of future-oriented coping and its mediating role in student engagement. Personality and Individual Differences, 43, 851-863.

Giga, S. I., Cooper, C. L., \& Faragher, B. (2003) The development of a framework for a comprehensive approach to stress management interventions at work. International Journal of Stress Management, 10(4), 280296.

Harris, J. R. (1991) The utility of the transaction approach for occupational stress research. Journal of Social Behaviour and Personality, 6, 21-29.

Heslop, R. (2010) They didn't treat us like professionals: a case study of police recruits trained at a university. Paper presented at the Fourth Critical Perspectives on Professional Learning Conference. Pp. 1-14. Retrieved from http://www.richardheslop.net/

Kaiseler, M., Polman, R., \& Nicholls, A. (2009) Mental toughness, stress, stress appraisal, coping, and coping effectiveness in sport. Personality and Individual Differences, 47, 728-733.

Kaiseler, M., Polman, R., \& Nicholls, A. (2012) Gender differences in stress, appraisal, and coping during golf putting. International Journal of Sport and Exercise Psychology, 1, 1-15.

Kline, R. B. (2005) Principles and practice of structural equation modeling, (2nd ed.) New York: Guilford Press.

Lazarus, R. S. (1991) Emotion and adaptation. New York: Oxford University Press.

Lazarus, R. S., \& Folkman, S. (1984) Stress, appraisal, and coping. New York: Springer.

LeBlanc, V. R., Regehr, C. R., Jelley, R. B., \& Barath, I. (2008) The relationship between coping styles, performance, and response to stressful scenarios in police recruits. International Journal of Stress Management, $15,76-93$.

Maas, H. H., \& Spinath, F. M. (2012) Personality and coping with professional demands: a behavioural genetics analyses. Journal Occupational Health Psychology, 17, 376-385.

McCarty, W. P., Zhao, J. S., \& Garland, B. E. (2007) Occupational stress and burnout between male and female police officers. Are there any gender differences? Policing: An International Journal of Police Strategies and Management, 30, 672-691.

Nerstad, C. G. L., Richardsen, A. M., \& Martinussen, M. (2010) Factorial validity of the Utrecht Work Engagement Scale (UWES) across occupational groups in Norway. Scandinavian Journal of Psychology, 51, 326-333.

Pais-Ribeiro, J., \& Rodrigues, A. (2004) Questioning coping: adaptation study of the Brief COPE. Psicologia: Saúde \& Doenças, 5, 3-15.

Parker, P. D., \& Martin, A. J. (2009) Coping and buoyancy in the workplace: understanding their effects on teachers' work-related well-being and engagement. Teaching and Teacher Education, 25, 68-75.

Patterson, G., Chung, I., \& Swan, P. G. (2012) The effects of stress management interventions among police officers and recruits. Campbell Systematic Reviews, 7, 3-27.

Penley, J. A., Tomaka, J. \& Wiebe, J. S. (2002) The association of coping to physical and psychological health outcomes: a meta-analytic review. Journal of Behaviour Medicine, 25(6), 551-603.

Richardsen, A. M., Burke, R. J., \& Martinussen, M. (2006) Work and health outcomes among police officers: the mediating role of police cynicism and engagement. International Journal of Stress Management, 13, 555574. 
Rothmann, S., Jorgensen, L. I., \& Hill, C. (2011) Coping and work engagement in selected South African organizations. SA Journal of Industrial Psychology, 37, 1-11.

Schaufeli, W. B. \& Bakker, A. B. (2003) UWES Utrecht Work Engagement Scale: Preliminary Manual. Utrecht, The Netherlands: Department of Psychology, Occupational Health Psychology Unit.

Schaufeli, W. B., Martínez, I. M., Marques Pinto, A., Salanova, M., \& Bakker, A. B. (2002) Burnout and engagement in University. students: a cross-national study. Journal of Cross-Cultural Psychology, 36, 464-481.

Seligman, P., \& Csikszentmihalyi, M. (2000) Positive psychology: an introduction. American Psychologist, 55, $5-14$.

Shimazu, A., Schaufeli, W. B., Kosugi, S., Suzuki, A. Nashiwa, H., Kato, A. et al., (2008) Work engagement in Japan: validation of the Japanese version of the Utrecht Work Engagement Scale. Applied Psychology: An International Review, 57, 510-523.

Sica, C., Novara,C., Dorz, S., \& Sanavio, E. (1997) Coping strategies: Evidence for crosscultural differences? A preliminary study with the Italian version of coping orientations to problems experienced (COPE). Personality and Individual Differences, 23(6), 1025-1029.

Thompson, S. C. \& Spacapan, S. (1991) Perceptions of control in vulnerable populations. Journal of Social Issues, 47, 1-21.

Toch, H. (2002) Stress in policing. Washington, DC: American Psychological Association.

Violanti, J. M. (1992) Coping strategies among police recruits in a high-stress training environment. The Journal of Social Psychology, 132, 717-729.

Carver, C., Scheier, M. \& Weintraub, J. (1989). Assessing coping strategies: A theoretically based approach. Journal of Personality and Social Psychology, 56(2), 267-283.

Wilson, J. M., \& Grammich, C. A. (2009) Police recruitment and retention in the contemporary urban environment: Personnel Experiences and Promising Practices from the Front Lines. Santa Monica, CA: U.S. Department of Justice, RAND Center on Quality Policing.

Yagil, D. (2012) The mediating role of engagement and burnout in the relationship between employees' emotion regulation strategies and customer outcomes. European Journal of Work and Organizational Psychology, 21, $160-168$.

Yusoff, N., Low, W.L., \& Yip, C.H. (2010). Reliability and Validity of the Brief COPE Scale (English Version) Among Women with Breast Cancer Undergoing Treatment of Adjuvant Chemotherapy: A Malaysian Study. Medical Journal of Malaysia, 65(1), 41-44. 
Stress in Police Recruits / M. Kaiseler, et al.

TABLE 1

Ranges, Means, Standard Deviations, Internal Consistency Reliabilities, Skewness, KuRtosis and Kolmogorov-SMirnov Test For EACH COPING AND ENGAGEMENT SubSCALE, StRESSOR INTENSITY, AND

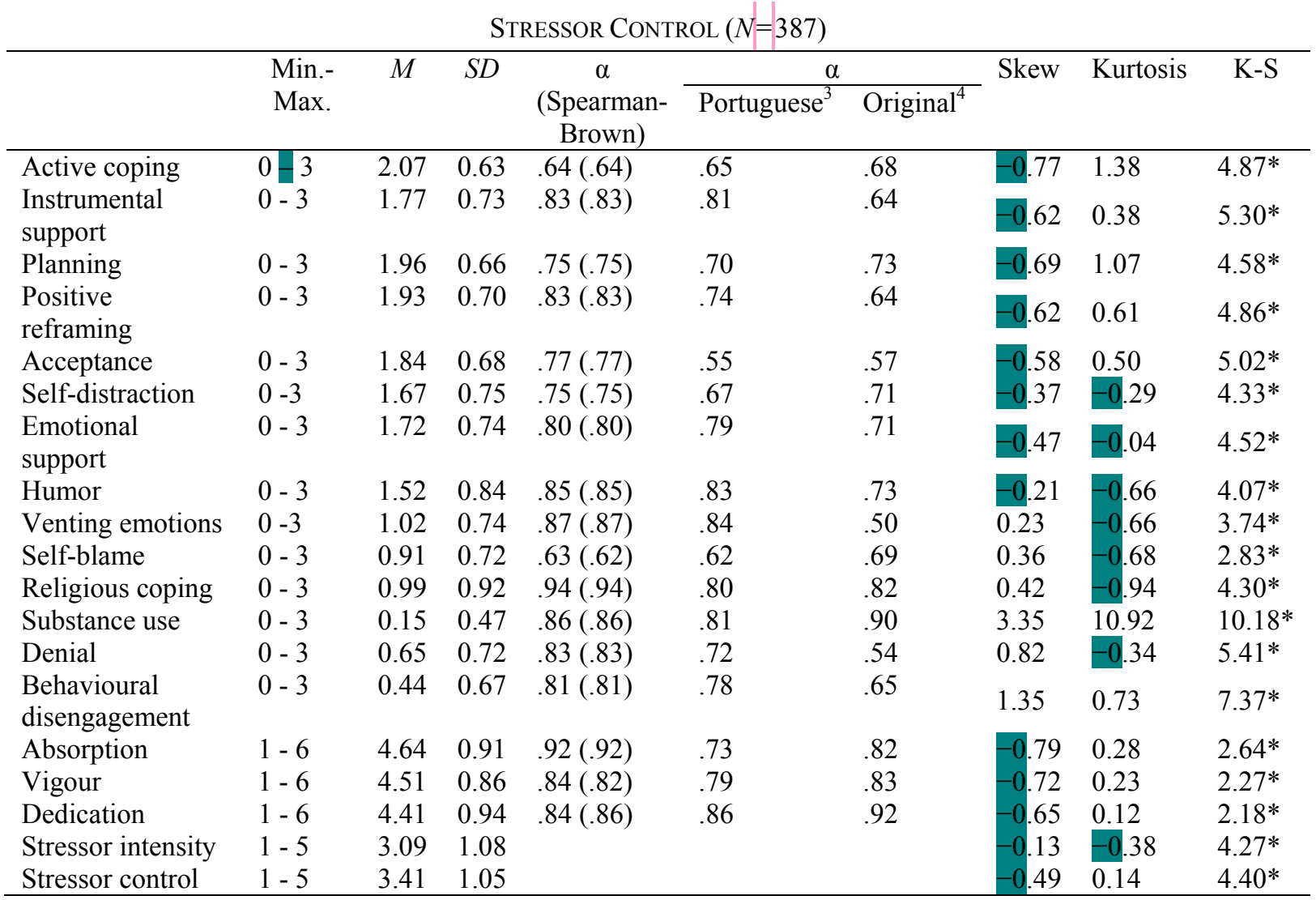

${ }^{*} p \mid<.001$.

\footnotetext{
${ }^{3}$ Portuguese versions of Brief Cope (Pais Ribeiro \& Rodrigues, 2004) or UWES (Schaufeli et al., 2002)

${ }^{4}$ Original versions of Brief Cope (Carver, 1997) or UWES (Schaufeli \& Bakker, 2003)
} 
Stress in Police Recruits / M. Kaiseler, et al.

TABLE 2

CORRELATIONS AMONG ENGAGEMENT AND Coping SubSCAlES, STRESSOR INTENSITY, AND StRESSOR CONTROL $(N=387)$

\begin{tabular}{|c|c|c|c|c|c|c|}
\hline \multirow{2}{*}{$\begin{array}{c}\text { Scale } \\
\text { Active coping }\end{array}$} & \multicolumn{2}{|c|}{ Absorption } & \multicolumn{2}{|l|}{ Vigour } & \multicolumn{2}{|c|}{ Dedication } \\
\hline & .28 & .001 & .23 & .001 & .22 & 001 \\
\hline Instrumental support & .15 & .002 & .14 & .005 & .12 & .02 \\
\hline Planning & .20 & .001 & .17 & .001 & .15 & .01 \\
\hline Positive reframing & .18 & .001 & .12 & .02 & .10 & .05 \\
\hline Acceptance & .09 & .10 & .06 & .24 & .05 & .34 \\
\hline Self-distraction & .04 & .48 & .02 & .77 & .03 & .56 \\
\hline Emotional support & .16 & .002 & .14 & .01 & .12 & .02 \\
\hline Humor & .01 & .86 & .02 & .65 & .02 & .70 \\
\hline Venting emotions & .12 & .02 & .06 & .25 & .09 & \\
\hline Self-blame & .13 & .01 & .14 & .01 & .07 & .18 \\
\hline Religious coping & .04 & .49 & .07 & .15 & .08 & .10 \\
\hline Substance use & .19 & .001 & .14 & .01 & .10 & .05 \\
\hline Denial & .21 & .001 & .14 & .01 & .13 & .01 \\
\hline $\begin{array}{l}\text { Behavioural } \\
\text { disengagement }\end{array}$ & .28 & .001 & .22 & .001 & -20 & .001 \\
\hline Stressor intensity & .05 & .29 & .02 & .66 & .04 & .43 \\
\hline Stressor control & .21 & .001 & .18 & .001 & .20 & .001 \\
\hline
\end{tabular}

Note.-Values of $p$ with Bonferroni correction. 
Stress in Police Recruits / M. Kaiseler, et al.

TABLE 3

Model Summary of Regression ANALysis For Engagement SubSCALES AS DePENDENT Variables AND Coping Strategies as Predictor VARIABles, Controlling For Stressor Control $(N=387)$

$$
\begin{array}{llllllll}
R^{2} & \operatorname{Adj} R^{2} & R^{2} \operatorname{chg} & B & S E & \beta & t & F(d f)
\end{array}
$$

Dependent Variable: Absorption

\begin{tabular}{|c|c|c|c|c|c|c|c|c|}
\hline Stressor control & .04 & .04 & .04 & .12 & .04 & .14 & $2.93+$ & \multirow{3}{*}{$23.46 \neq(3.39)$} \\
\hline $\begin{array}{l}\text { Behavioural } \\
\text { disengagement }\end{array}$ & .11 & .11 & .07 & -32 & .06 & .24 & $-4.99 \neq$ & \\
\hline Active coping & .16 & .15 & .04 & .30 & .07 & .21 & $4.30 \ddagger$ & \\
\hline \multicolumn{9}{|c|}{ Dependent Variable: Vigour } \\
\hline Stressor control & .03 & .03 & .03 & .10 & .04 & .12 & $2.48 \ddagger$ & \multirow{5}{*}{$10.68 \neq(5.39)$} \\
\hline $\begin{array}{l}\text { Behavioural } \\
\text { disengagement }\end{array}$ & .08 & .07 & .04 & .20 & .07 & 0.15 & $-2.76 \dagger$ & \\
\hline Active coping & .10 & .10 & .03 & .25 & .07 & .18 & $3.57 \neq$ & \\
\hline Self-blame & .11 & .10 & .01 & a.15 & .07 & .12 & $2.27 \dagger$ & \\
\hline Religious coping & .12 & .11 & .01 & .10 & .05 & .11 & $2.14 \dagger$ & \\
\hline \multicolumn{9}{|c|}{ Dependent Variable: Dedication } \\
\hline Stressor control & .04 & .04 & .04 & .13 & .04 & .15 & $2.97 \dagger$ & \multirow{4}{*}{$11.11 \ddagger(4.39)$} \\
\hline Behavioural & .07 & .07 & .03 & -25 & .07 & 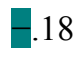 & $-3.60 \neq$ & \\
\hline Active coping & .10 & .09 & .02 & .21 & .08 & .14 & $2.82 \dagger$ & \\
\hline Religious coping & .10 & .10 & .01 & .10 & .05 & .10 & $2.00 *$ & \\
\hline
\end{tabular}

$* p<.05 . \dagger p<.01 . \neq p<.001$. 